\title{
PRE-SERVICE MATHEMATICS TEACHERS' KNOWLEDGE OF MATHEMATICS FOR TEACHING: QUADRATIC FUNCTIONS
}

\author{
Ifunanya Julie Adaobi Ubah, Sarah Bansilal \\ University of Kwazulu-Natal, South Africa \\ E-mail: adaichieify2000@gmail.com, BansilalS@ukzn.ac.za
}

\begin{abstract}
Many researchers and education stakeholders in South Africa point to the need to develop teachers personal knowledge of the mathematics concepts that they teach to their learners. In this research study we explore the understanding of 42 pre-service mathematics teachers of one aspect of school level mathematics, that of quadratic functions. Data were generated from the written responses to an assessment as well as semi-structured interviews. The purpose was to explore the methods used by pre-service mathematics teachers to derive a symbolic equation for a quadratic function expressed in graphical form. Furthermore, we looked at whether the pre-service teachers were able to use different methods to generate the symbolic equation. The results showed that 25 participants were able to determine the equation of a parabola using one method, while 11 of them were able to use two different methods. The most common method used was based on the intercept form of the equation. Some students identified different forms that the equation of a quadratic function could be expressed as but were unable to apply this to derive the equation. These results indicate that these students are not yet ready to teach these school level concepts even though they have studied advanced mathematics topics as part of their pre-service training. The study recommends that pre-service teachers should also be provided with more structured opportunities to help develop pedagogic content knowledge of the school level content as part of their teacher training programme.
\end{abstract}

Keywords: graphical representation, parabola, pre-service mathematics teachers, quadratic functions, symbolic representation.

\section{Introduction}

In many developing countries such as South Africa, teachers who do not have a sufficiently robust knowledge of basic mathematics are recruited into the teaching profession because of the large demand for qualified teachers (Bowie \& Reed, 2016; Deacon, 2016; Ndlovu, Amin, \& Samuel, 2017). Hence many teacher education institutions are struggling to break the "cycle of mediocrity, where school leavers who were themselves poorly taught are returned to the schools as poorly prepared teachers" (Deacon, 2016, p.25). This research is situated in the context of under-prepared pre-service mathematics teachers who are struggling themselves with the school level mathematics that they are expected to teach.

Changes in the mathematics curriculum for South African schools brought in a more flexible and connected way of looking at quadratic functions as the curriculum includes the study of translations of various graphs, where learners are expected to understand the effects of various parameters on the graphs (Kunene \& Bansilal, 2015). These curriculum changes place further demands on teachers so that they can facilitate this flexible understanding of the quadratic function. Kunene and Bansilal found out that the learners preferred to generate new graphs by going through a step by step procedure based on substitution using a table instead of carrying out vertical or horizontal translations on the original graph to find the quadratic 
Ifunanya Julie Adaobi UBAH, Sarah BANSILAL. Pre-service mathematics teachers' knowledge of mathematics for teaching: Quadratic functions

PROBLEMS

OF EDUCATION

IN THE $21^{\text {st }}$ CENTURY Vol. 76, No. 6, 2018

848

who observed that learners who knew some rules related to solving quadratic functions, were able to apply these rules without thinking about why they did so, or whether what they were doing was mathematically correct.

Since the concept of quadratic equations and the graphs of parabolas are important ideas that permeate much of the mathematics studied in the further education and training (FET) band in South African schools, there is a need to explore pre-service FET mathematics teachers' knowledge of the concepts. Many research studies argue that teachers' understanding of the concepts should go beyond what is taught to their learners, because they have to respond to demands different from just being able to solve a problem (Ball, Thames, \& Phelps, 2008; Ndlovu et al., 2017; Bansilal, Brijlall, \& Mkhwanazi, 2014). Some of the demands are associated with the pedagogical content knowledge (PCK) of these concepts (Shulman, 1986). For example, teachers need to understand the various representations of functions; to move flexibly between different representations; to know different methods of solving problems; to know which method is easier than another; to recognise whether different methods are equivalent or not; and, to be able to explain under what conditions certain procedures are appropriate or not. The purpose of this research was to explore the methods used by pre-service mathematics teachers to derive a symbolic equation for a quadratic function expressed in graphical form. Furthermore, we looked at whether the pre-service teachers were able to use different methods to generate the symbolic equation.

\section{The Quadratic Function}

Variables can be expressed in terms of lists of numbers, tables, set of order pairs, a flow diagram or a graph. A function is an expression which describes the relationship between two or more variables; where an independent (input) variable has exactly one dependent (output) variable. When expressions between variables can be expressed as functions, they can be visualised in the form of graphs which are usually easier to read than lists of numbers, tables, flow charts or sets of ordered pairs. A quadratic function is one of the form $\mathrm{f}(x)=a x^{2}+b x+$ $c$, where $\mathrm{a}, \mathrm{b}$, and $\mathrm{c}$ are numbers with a not equal to zero (Nielsen, 2015; Pender, Saddler, Shea $\&$ Ward, 2011). In a quadratic function, the greatest power of the variable is 2 and may be one, two or no real roots. The graph of a quadratic function, $y=a x^{2}+b x+c$, is a parabola (Yeo, Seng, Lee, \& Chow, 2013).

The quadratic function, can also be expressed in factored or Intercept form if it has roots as $\mathrm{f}(x)=a\left(x-x_{1}\right)\left(x-x_{2}\right)$, where $x_{1}$ and $x_{2}$ are the roots of the quadratic function and the solutions of the corresponding quadratic equation (Ousby, Cross, \& Bowman, 2008). The intercept form of a quadratic equation is one by which you can easily tell the $\mathrm{x}$ intercepts of the quadratic function. It is also very easy to get the equation of the axis of symmetry of a parabola from the intercept form of a quadratic function (Parent, 2015). A quadratic function could be in vertex form as $f(x)=a(x-p)^{2}+q$, which is so named because $p$ and $q$ directly give you the coordinates of the vertex or turning point of the function since the vertex of the graph is located at the point $(\mathrm{p}, \mathrm{q})$. The vertex of a parabola is the place where it turns; hence, it is also called the turning point.

The concept of quadratic function is one of the most important ideas in school mathematics as graphs and equations are important parts of mathematics (Benning \& Agyei, 2016; Nielsen, 2015; Parent, 2015). The idea of quadratic function plays an important role in the development of mathematical concepts in that it cuts across a range of mathematics content domains including those of algebra and geometry (National Council of Teachers of Mathematics (NCTM), 2000). Mathematics teachers'understanding of quadratic functions is critical for student success in mathematics and there appears to be agreement that for many high school students, solving 
and understanding quadratic functions can be conceptually challenging because of the need to make connections between various representations of the function as well as connections between the various forms in which the quadratic equation can be expressed as. (Didis, Bas, \& Erbas, 2011; Kilic, 2009).

\section{Literature Review}

In South Africa, there is little evidence to show that much progress have been made at the level of the learners as revealed on results of summative national and international learners' achievement, such as the Southern Africa Consortium for Monitoring Education Quality (SACMEQ), and the National Senior Certificate (NSC) Examinations (Alex \& Mammen, 2016; Pournara, Hodgen, Adler, \& Pillay, 2015). Learners' low levels of progress in national and summative examinations can be attributed, at least in part, to teachers' poor mathematical knowledge (Taylor \& Taylor, 2012) and there are instances where it has been shown that teachers don't know well enough, the mathematics their learners need to learn (Bansilal, Brijlall, \& Mkhwanazi, 2014; Lowrie \& Jorgensen, 2016; Taylor \& Taylor, 2012). One of the expectations of the Department of Basic Education (2011) is that the teachers be knowledgeable of the content they are teaching. Across the world there are concerns about improving teachers' mathematical knowledge (Agyei \& Voogt, 2012; NCTM, 2000; Pournara, Hodgen, Adler, \& Pillay, 2015; Shulman, 1986).

Considering these concerns, there is a need to understand pre-service mathematics teacher education (PSMTE) programmes offered in South Africa and how these prepare teachers to teach in schools. This study was located within a Bachelor of Education (B.Ed) degree which is a four- year programme designed to prepare students to become teachers. The B.Ed programme comprises a mix of courses based on the students' specialization subjects, educational theories, teaching methodologies and teaching practice. In the case of mathematics teachers, the modules focus on university level mathematics content; knowledge about school level mathematics content and how to teach it; as well as educational, psychological and sociological principles and theories about students and how they learn. Modules based on methods of teaching school mathematics form a small part of the degree comprising about $10 \%$ of the required credits needed to complete the degree.

The concept of quadratic functions and parabola chosen for this study was because it serves as an entry point to the study of polynomial functions in mathematics (Iben, 2012; Zaslavsky, 1997). Moreover, functions are the foundation for all mathematics fields and have many uses in career-related courses. A sound understanding of quadratic functions will enable learners to deal with different types of functions such as trigonometric functions, linear functions, exponential functions and logarithmic functions, leading to an understanding of real-life uses of this concept. In view of these reasons, the concept of quadratic functions and parabola was chosen for this research. The task used for this research was adapted from the National Certificate mathematics examination for Grade 12 learners. The aim is to find out if the proposed teachers who will teach these learners after graduating in few months really understand the content that they are meant to teach.

Some research focus on procedural aspects of solving quadratic equations, how students understand variables, graphs and quadratic functions (Leinhardt \& Zaslavsky, 1990; Siyepu, 2013; Yuksel \& Danyal, 2011). Mudaly and Rampersad (2010) conducted a study with Grade 11 learners in South Africa, exploring learners' conceptual understanding of graphical representations of functional relationships. The findings indicated that the learners relied on procedural knowledge to explain simple concepts and their visual understanding was weak and dependent on diagrams that teachers use in the classroom. Mudaly and Rampersad recommended that teachers should focus on developing visualization skills in the teaching and 
Ifunanya Julie Adaobi UBAH, Sarah BANSILAL. Pre-service mathematics teachers' knowledge of mathematics for teaching: Quadratic functions

PROBLEMS

OF EDUCATION

IN THE $21^{\text {st }}$ CENTURY Vol. 76, No. 6, 2018

850

learning of graphical representations of functions that they believed was essential for conceptual understanding.

Dede and Soybas (2011) carried out a study on the experience of mathematics preservice teachers in relation to function and equation concepts and the relationship between them. Data were collected using questionnaires and semi-structured interviews and analysed through existential-phenomenology. The study revealed that many pre-service teachers have incorrect conceptions and vague ideas about quadratic function and only a few students gave a mathematically sound definition of equation.

Bansilal (2012) explored how a teacher with poor mathematical knowledge taught mathematics for understanding. Bansilal found that the teacher did not formulate clear explanations, and also omitted key ideas when trying to help students. Bansilal suggested that a collegial and supportive environment is important for such teachers' further development. Teachers with poor content knowledge also need more detailed explanations, and such explanations are also important for the students.

Sibuyi (2012) studied teachers' knowledge of learners' conceptions and misconceptions on the topics of quadratic functions using questionnaire and semi-structured interview. The findings revealed that many teachers were unable to detect misconceptions of the learner when analysing their learners' responses to the questions. In addition, Prediger (2010) found out that pre-service teachers have difficulties in properly analysing their learner's responses so as to diagnose misconception.

Parent's (2015) study examined how students develop a conceptual understanding of the graph of the quadratic function. Qualitative research methods that utilized think-aloud protocols while students were engaged in four tasks pertaining to the quadratic function were employed. Results suggested that students preferred the standard form to vertex form when solving problems on quadratic functions and often confused the y-intercept of the standard form with the y-coordinate of the vertex when the function was in vertex form. Celik and Guzel (2017) conducted a study on students' thoughts of a quadratic function using a clinical interview. Celik and Guzel observed that it is necessary for students to convert the standard forms to factorized forms or the vertex forms and to relate them with the graphical properties for improving their thinking about quadratic functions. The results suggest that explicit teaching of quadratic functions and the tasks related to the concept are important for conceptual learning.

The review of the literature revealed a small amount of research on pre-service teachers' understanding of the graphs of quadratic functions and links between the graphical and symbolic representations. The studies indicated that learners at all levels of education have difficulties in determining the relationship between drawing the graph of a parabola and using the graph to find the equation of the parabola. Moreover, it has been a challenging task for teachers to help their learners understand the connections between the graphical and symbolic representations of the quadratic function in a flexible way. Hence there was a need to explore the understanding of pre-service mathematics teachers in this area. This research used an exploratory framework that can be used to find out more about how students work with equations of quadratic functions.

\section{Research Questions}

This research responded to the research questions:

1. What methods do pre-service mathematics teachers use to derive a symbolic equation for a quadratic function expressed in graphical form?

2. To what extent can the pre-service teachers use different methods to generate an appropriate symbolic equation? 


\section{Research Methodology}

\section{Research Design}

A qualitative research method in general and case study approach in particular were used to find out pre-service mathematics teachers' main difficulties and weakness in finding the equation of a given parabola. Qualitative research methods permit an in-depth investigation of single or small number of units at a point (over a period) in time (Hsieh \& Shannon, 2005).

\section{Selecting Participants}

This exploratory research was carried out with 42 pre-service mathematics teachers (purposively sampled) who were enrolled in a mathematics method course forming part of their Bachelor in Education (B.Ed.) degree at a South African University. In this research, the participants for the interview were selected based on the purposeful sampling strategy. The purpose of purposeful sampling is to select information-rich cases whose study will illuminate the questions under study (Ratcliff, 2016). Six pre-service teachers were selected for the semistructured interview based on their responses to the written test administered.

\section{Ethical considerations}

Permission to conduct the study was obtained from the university which has a strict protocol that had to be adhered to. While the written test was part of continuous assessment at the end of the module, informed consent was sought from the pre-service teachers. They were asked to give consent to having their scripts analysed and to be interviewed as well as to have the interview recorded. The purposes of the study were explained at the beginning of the semester and the participants were aware that participation was voluntary. However, all the pre-service teachers who registered for the module, participated in the research. To protect the participants' identities, all names used in this article are pseudonyms.

\section{Data Collection}

The data collected from the pre-service teachers' written responses to a task which formed part of an assessment that was intended to probe their knowledge and understanding of quadratic functions and parabola. Six pre-service teachers were purposefully selected for interviews based on their written responses to the assessment item. The participants for the semi-structured interview consisted of one high achiever, two average achievers and three lower achievers.

\section{Data Analysis}

Analysis of data entails breaking down the information gathered into elements in order to obtain responses to research questions (Sauro, 2015). In this study, the quantitative data from written responses and interviews were analysed using content analysis. The interview data were organized in order to get an overview of what it revealed, and test responses were grouped into manageable themes (Ratcliff, 2012). The details of the task are presented below in Tables 1 and 2 and Figure 1. 
Ifunanya Julie Adaobi UBAH, Sarah BANSILAL. Pre-service mathematics teachers' knowledge of mathematics for teaching: Quadratic functions

OF EDUCATION

IN THE $21^{\text {st }}$ CENTURY

Vol. 76, No. 6, 2018

Task.

\section{Table 1: Assessment Task}

A parabola (in figure 1 below) intersects the $x$-axis at $B$ and $C$ and the $y$-axis at $E$. The axis of symmetry of the parabola has equation $=3$. The line through $E$ and $C$ has equation $g(x)=\frac{x}{2} \quad-\frac{7}{2}$ Using the information on the graph; find the equation of the parabola using two different methods.

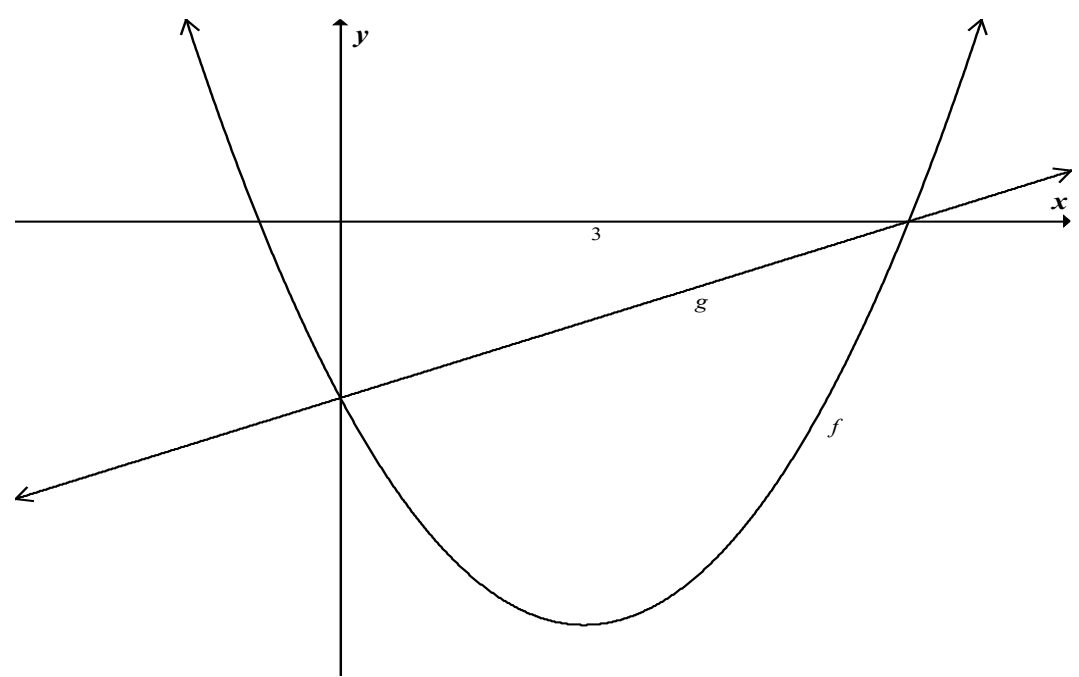

Figure 1. Graph of a parabola.

\section{Expected Responses to the Task}

There are three different forms of the quadratic equation that can be used to find the equation of the graph of the parabola. The pre-service teachers were expected to use any two different methods to find the equation of the parabola above. The methods are named according to three basic forms of a parabola equation namely:

1. Vertex form: when the parabola is in vertex form, the equation is written as $y=(x-p)^{2}+q$, where $(p ; q)$ are the coordinates of the turning point of the parabola.

2. Intercept form: sometimes referred to as the factor method. It involves the points where the curve cuts $\mathrm{x}$-axis. The parabola equation at this form is factored and it is written as $y=a(x-$ $\left.x_{1}\right)\left(x-x_{2}\right)$, where the coordinates of the $\mathrm{x}$-intercepts are $\left(\mathrm{x}_{1}, 0\right)$ and $\left(\mathrm{x}_{2}, 0\right)$.

3. Standard form: this is the general form of parabola equation; the equation is written in the form $y=a x^{2}+b x+c$.

There were three different methods that could be used in solving the problem-the intercept method (IM), the vertex method (VM) and the standard form method (SM). These are explained in further detail together with comments in Table 2 below: 
Ifunanya Julie Adaobi UBAH, Sarah BANSILAL. Pre-service mathematics teachers' knowledge of mathematics for teaching: Quadratic functions

Table 2. Possible responses.

\section{Possible Responses}

Note that $p=3$, since $x=3$ is the equation of symmetry

(a). Using the vertex method to derive the equation of the parabola in the form $y=a(x-p)^{2}+q$.

Using the given equation of the line, $g(x)=\frac{x}{2}-\frac{7}{2}$, one can find the coordinates of the points $E$ and $C$

To find the coordinates of $E$, set $x=0$

$y=\frac{0}{2}-\frac{7}{2}, y=-\frac{7}{2} \quad \therefore E\left(0,-\frac{7}{2}\right)$
To find coordinates of $C$, set $y=0$

Then $0=\frac{x}{2}-\frac{7}{2}$, therefore, $\frac{7}{2}=\frac{x}{2}$ hence $\mathrm{x}=7 \therefore \mathrm{C}(7,0)$

Substituting the points $\mathrm{E}$ and $\mathrm{C}$ into the equation, two equations can be generated in terms of $a$ and $q$ :

$$
=9 a+q \ldots . . . e q n(1)
$$

$0=16 a+q \ldots . . e q n(2)$

By solving these equations simultaneously, it can be seen that $a=1 / 2$ and $q=-8$.

Finally, we substitute the values of $a, q$ and $c$ into the vertex form to get equation

$f(x)=a(x-p)^{2}+q$ that is, $f(x)=1 / 2(x-3)^{2}-8$ or $f(x)=1 / 2 x^{2}-3 x-\frac{7}{2}$.

Using the given equation of the line $g(x)=\frac{x}{2}-\frac{7}{2}$, one can find the coordinates

of $C$ by solving for $x$ in the equation, $g(x)=0$

$0=\frac{x}{2}-\frac{7}{2}, 0=x-7 \therefore x=7 C(7,0)$

By iñspection the coordinates of $B(-1,0)$

(b). Using the Intercept method to find the equation in the form: $y=a\left(x-x_{1}\right)\left(x-x_{2}\right)$. Hence the equation will be $g(x)=a(x+1)(x-7)$.

Substituting the point $E\left(0,-\frac{7}{2}\right)$ to find ' $a$ ':

$-\frac{7}{r}=a(0+1)(0-7), \therefore a=1 / 2$

Hênce the complete equation is:

$g(x)=y=1 / 2(x+1)(x-7)$, that is

$y=1 / 2\left(x^{2}-6 x-7\right)$ then $y=1 / 2 x^{2}-3 x-\frac{7}{2}$.

Using the given equation $g(x)=\frac{x}{2}-\frac{7}{2}$, find the coordinates of point $C$ by solving for $x$ in the equation, $g(x)=0$

(c). Finding $a, b$ and $c$ using three points to find the equation in the standard form $y=a x^{2}+$ $b x+c$ $0=\frac{x}{2}-\frac{7}{2}$, then $\frac{7}{2}=\frac{x}{2}$, hence $\mathrm{x}=7 \mathrm{C}(7,0)$

By inspection, the coordinates of $B$ is $(-1,0)$

By substituting these coordinates into the standard form of the equation, values of $a$ and $b$ can be found

So, $f(x)=1 / 2 x^{2}-3 x-\frac{7}{2}$. 
Ifunanya Julie Adaobi UBAH, Sarah BANSILAL. Pre-service mathematics teachers' knowledge of mathematics for teaching: Quadratic functions

PROBLEMS

OF EDUCATION

IN THE $21^{\text {st }}$ CENTURY

Vol. 76, No. 6, 2018

854

\section{Research Results}

\section{Overall Summary of the Results of the Written Responses}

In reporting the results, the references to the pre-service teachers contain a number from 1 to 42 , so T5 for example, refers to the fifth teacher. The scripts were not arranged in any particular order, and a higher or lower number does not indicate any difference in ability or performance.

There were three different methods that students could use to find the equation of the quadratic function from the graph as explained in Table 2 and are referred to as the intercept method (IM), the vertex method (VM) and standard form method (SM). The researchers looked at the different methods chosen by the students and whether the solution they obtained was correct or not, for each of the methods they chose. Table 3 presents the results for all these categories:

Table 3. Results based on methods of finding the equation of the parabola.

\begin{tabular}{lllll}
\hline Method & $\begin{array}{l}\text { Number of participants } \\
\text { that identified any cor- } \\
\text { rect method }\end{array}$ & $\begin{array}{l}\text { Number of partici- } \\
\text { pants that provided } \\
\text { correct solution for } \\
\text { any of the method } \\
\text { identified }\end{array}$ & $\begin{array}{l}\text { Number of partici- } \\
\text { pants that provided } \\
\text { correct method but } \\
\text { incorrect solution }\end{array}$ & $\begin{array}{l}\text { Number of partici- } \\
\text { pants that provided } \\
\text { incorrect method } \\
\text { and solution }\end{array}$ \\
\hline Vertex & 10 & 7 & 3 & 4 \\
\hline Intercept & 22 & 15 & 7 & 7 \\
\hline Standard & 5 & 3 & 2 & 1 \\
\hline
\end{tabular}

From table 3, it can be seen that the most common method was the intercept method, which 29 out of the 42 participants opted to use, while 14 used the vertex method and six 6 participants chose the standard form method. It was found that of the 29 participants who chose the intercept method, 22 participants presented the correct intercept form of the equation while 7 presented an incorrect formula. With respect to the vertex method, 10 correctly stated the vertex method while 4 gave an incorrect formula. For the 6 out of 42 participants that identified the standard form method; 5 identified the correct standard form method while 1 gave incorrect method $\left(y=x^{2}+b x+c=0\right)$. Hence, it can be seen that many students did not know the various formulae that could be used to derive the equation of a quadratic function.

Following up, it can be seen that many of the students who correctly identified the formula were able to use it correctly in deriving the equation of the function. For the intercept method, 15 out of the 22 that stated correctly the intercept form were able to use it to find the parabola equation of the parabola, while 7 that provided the correct intercept form could not find the equation of the parabola. From the 10 participants that stated the vertex method correctly, 7 used it to find the correct equation of the parabola while 3 used the correct method but could not find the equation of the parabola. Out of the 5 that stated the standard form correctly, 2 could not use it to find the equation of the parabola while 3 used the method to find the equation of the parabola. Hence it can be seen that irrespective of which method the students chose; more than half of them were able to use their method to find the equation of the quadratic function. Table 3 also indicate clearly that 25 students were able to solve the problem using one method. This number dropped by more than half to 11 when it came to using two different methods to solve the problem correctly (see Table 4). 
Ifunanya Julie Adaobi UBAH, Sarah BANSILAL. Pre-service mathematics teachers' knowledge of mathematics for teaching: Quadratic functions

Table 4. Results based on two methods of finding the equation of the parabola.

\begin{tabular}{lllll}
\hline Method & $\begin{array}{l}\text { Number of } \\
\text { participants that } \\
\text { identified any two } \\
\text { correct methods }\end{array}$ & $\begin{array}{l}\text { Number of partici- } \\
\text { pants that provided } \\
\text { correct solution for } \\
\text { any two identified } \\
\text { methods }\end{array}$ & $\begin{array}{l}\text { Number of partici- } \\
\text { pants that provided } \\
\text { correct methods } \\
\text { but incorrect solu- } \\
\text { tion }\end{array}$ & $\begin{array}{l}\text { Number of partici- } \\
\text { pants that provided } \\
\text { incorrect methods } \\
\text { and solution }\end{array}$ \\
\hline Vertex \& Intercept & 26 & 9 & 17 & 16 \\
\hline Vertex \& Standard & 7 & 1 & 6 & 35 \\
\hline Intercept \& Standard & 4 & 1 & 3 & 38 \\
\hline
\end{tabular}

Table 4 revealed that out of the 26 participants that identified the vertex and intercept method to find the equation of the parabola; 9 participants used the two different methods correctly to find the required equation of the parabola while 17 were unable to use the methods correctly to find the equation of the parabola. 7 participants identified the vertex and standard methods to find the equation of the parabola; out of which 1 used the two methods correctly, while 6 were unable to use the two different methods to find the equation of the parabola. Consequently, 4 participants identified the intercept and standard form to find the equation of the parabola; out of which, 1 used the methods correctly; while 3 of them could not. An indication that fewer participants could use varied methods to find the equation of a given parabola.

\section{Results of the Interviews}

When one of the participants (T21) were probed during the interview about his performance in the written task, he replied that he "was blank" and preferred using an equation to draw the parabola but struggled to use the parabola to find equation which is a difficult task.

The dialogue between the researcher (R) and participant (T5) appears in Box 1. 
Ifunanya Julie Adaobi UBAH, Sarah BANSILAL. Pre-service mathematics teachers' knowledge of mathematics for teaching: Quadratic functions

PROBLEMS

OF EDUCATION

IN THE $21^{\text {st }}$ CENTURY

Vol. 76, No. 6,2018

856

Box 1: Dialogue between participant T5 and the researcher.

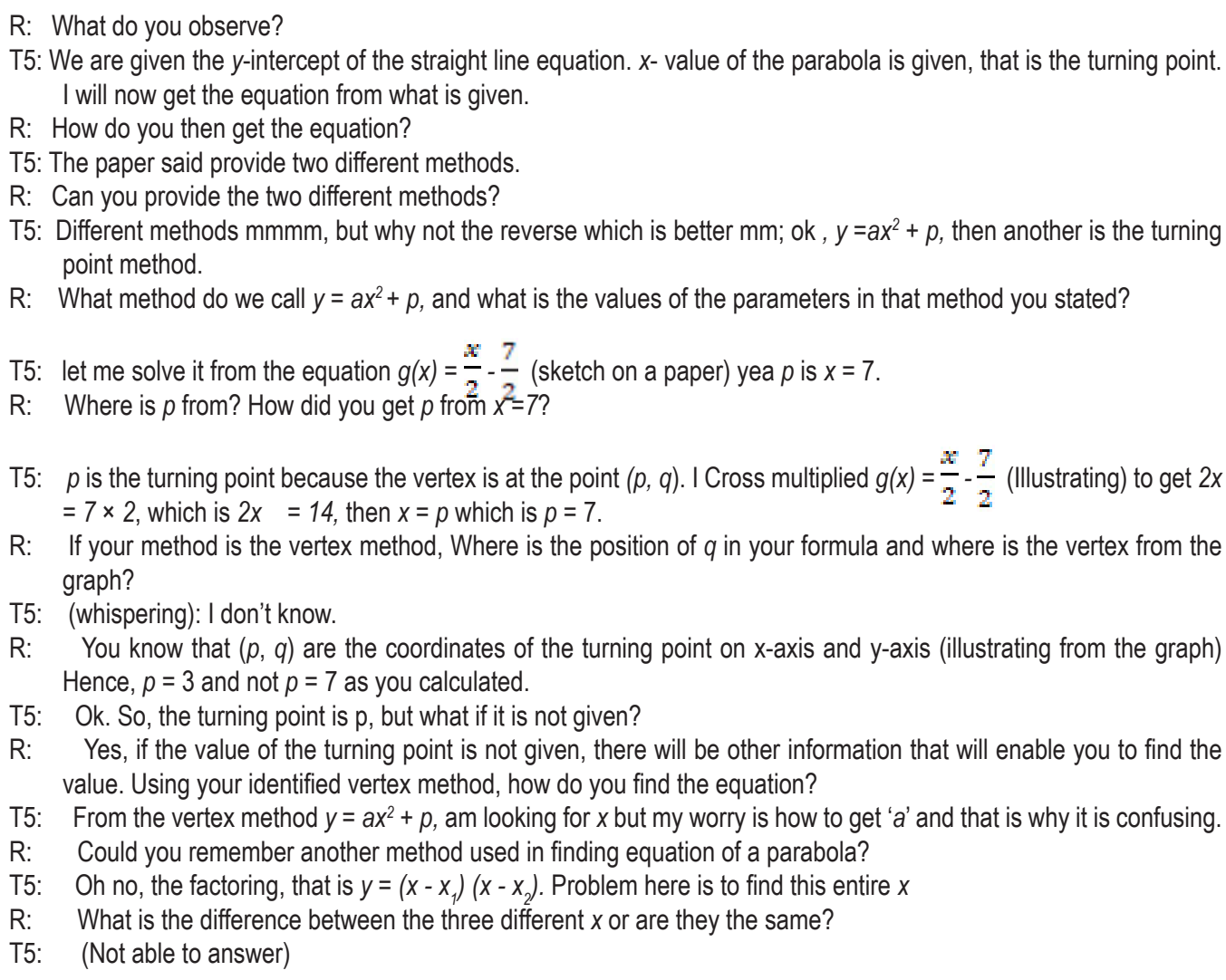

The dialogue appearing above showed that the student was confused between the parameters $p$ and $q$ in the vertex form of the equation. The student considered the vertex form as $y=a x^{2}+p$ instead of $y=a(x-p)^{2}+q$, and the intercept form was stated as $y=(x$ $\left.-x_{1}\right)\left(x-x_{2}\right)$ instead of $y=a\left(x-x_{1}\right)\left(x-x_{2}\right)$. The first misconception is that the equation of the parabola that the student used, describes a parabola whose axis of symmetry is the y-axis, whereas in this question, the parabola is not centred on the $y$-axis. Secondly, the student seems to be confused about parameters $p$ and $q$. He mentions $p$ but cannot connect it to the point on the graph. Thirdly, the student in describing the intercept form disregarded the parameter ' $a$ ' that determines the vertical stretching of the graph. Another interesting misconception was the confusion between the equation of the straight line and the calculation of the parameter $p$ which usually refers to the $x$-co-ordinate of the vertex of the parabola. The student in Box 1, has explained that he solved for $\mathrm{x}$ in the equation $g(x)=0$ to obtain the answer $x=7$ which he then took as the p-value in the function $f(x)$, however $x=7$ is the $x$-intercept of the line as well as the parabola.

\section{Analysis of Individual Written Responses to the Task}

The written responses of participant $\mathrm{T} 5$ and $\mathrm{T} 21$ that mentioned during the interview that he was blank at the time of the written task are shown in figures 2 and 3. 
3.1 Provide two different methods of working out Question (a)

$$
\begin{aligned}
& \text { Forst method will be upe } x \text {-inter cepts, B( } 1: 0) \text { yc }(7: 0) \\
& \begin{array}{l|l}
y=(x-1)(x-7) & f\left(x^{2}-2\right)=0 \\
=x^{2}-7 x \rightarrow x+7 & \left(x^{2}-2\right)^{2}-8\left(x^{2}-2\right)+7=0 \\
f(x)=x^{2}-8 x+7 & x^{4}-4 x^{2}+4-8 x^{2}+16+9=0 \\
& x^{4}-12 x^{2}+11=9 .
\end{array}
\end{aligned}
$$

Figure 2. Written response of participant T5 .

$$
\begin{aligned}
& \text { 3.1 Provide two different methods of working out Question (a) } \\
& \text { USing the } \frac{x-\text {-n tercepts }}{\text { method. }} B(-1,0) \& C(7,0) \text { and subsitute into } \\
& \text { equation. } y=a x^{2}+q \text { or } y=a x^{2}+b x+c
\end{aligned}
$$

Figure 3. Written response of participant T21.

In figure 2 the participant (T5), could not identify the point $(0,3)$ as the mid-point of line $B C$, hence was not able to get the correct coordinates of point $B(-1,0)$ but found point $C(7,0)$ correctly. Using an incorrect formula for the intercept form, he struggled to substitute numbers and arrived at an incorrect equation. The response of participant T21 in figure 3 reveals confusion which he described in his interview. His comment was that he could not think and was blank at that point when presented with the task. The response shows a reference to the $\mathrm{x}$-intercepts followed by an incorrect formula for the vertex form of the equation - confirming that he did not quite know what to do. The two responses of (T5 and T21) show that they both ignored the parameter ' $a$ ' which determines the vertical stretching of the graph.

Responses by three participants (T38, T10 and T24) appearing in Figures 4, 5, 6 and 7 , shows how they used incorrect methods to find the required equation. When the researcher probed T38 during the interview session, about the vertex and intercept forms of the equation, he was able to provide specific examples; for the vertex form he gave the equation $g(x)=2(x-$ $1)^{2}+3$ while an example of a quadratic function in an intercept form was given as $g(x)=2(x+3)$ $(x-1)$. However, he could not effectively use them to find the equation as is shown in figure 4.

3.1 Provide two different methods of working out Question (a)

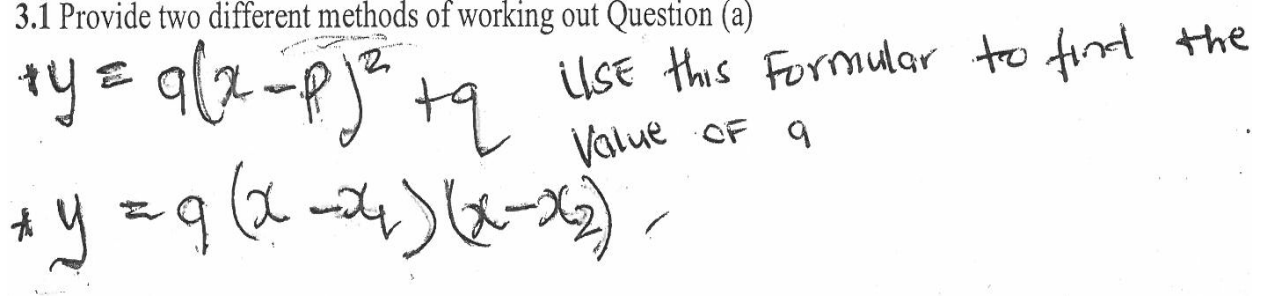

Figure 4. Written response of participant T38. 
Ifunanya Julie Adaobi UBAH, Sarah BANSILAL. Pre-service mathematics teachers' knowledge of mathematics for teaching: Quadratic functions

PROBLEMS

OF EDUCATION

IN THE $21^{\text {st }}$ CENTURY Vol. 76, No. 6, 2018

The written response of the pre-service student (T10) showed a different vertex form but she provided the appropriate standard form of the equations. With the standard form she used the correct coordinates of point $\mathrm{E}$ and calculated the value of $\mathrm{c}$ in the equation as $-7 / 2$. She then substituted correctly into the equation using the coordinates of $C$ to arrive at an equation in terms of the unknowns a and b, but struggled in going further, because she needed to substitute a further point to arrive at a second equation in terms of $a$ and $b$ which would have enabled her to solve the two equations simultaneously. Finding herself stuck, she then moved to using the vertex form of the equation, which was incorrectly formulated. During the interview, the participant T10 admitted that she had conflicting issues with the standard form and the incorrect vertex form. She explained that she learnt how to find equations of quadratic function using the standard form only and now realized the importance of being familiar with the different forms of representing the same equation.

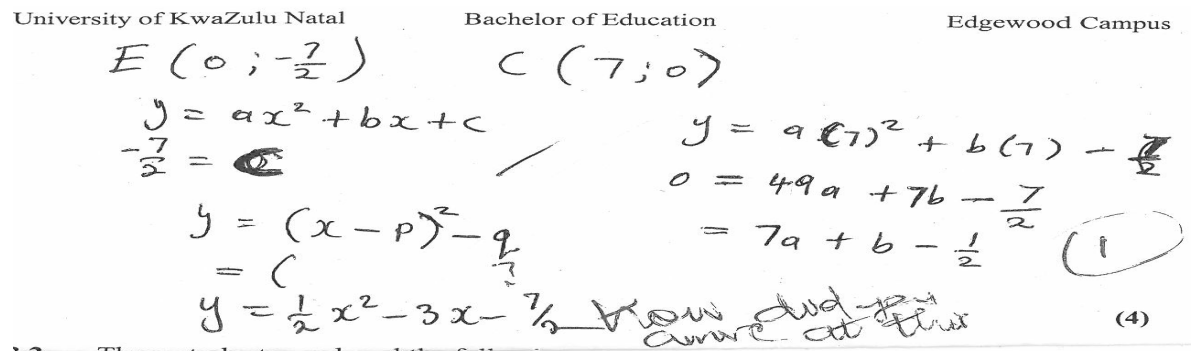

Figure 5. Written response of participant T10.

The approach of T24 appearing in figure 7, in providing two different methods of working out Question 1 is very interesting. The participant stated the intercept form but omitted the parameter ' $a$ ' and could not identify that $\mathrm{x}_{1}$ and $\mathrm{x}_{2}$ are the roots of the parabola and instead associated them with the straight line equation $g(x)=\frac{x}{2}-\frac{7}{2}$ that was given. The participant explained as part of her written response that she took the gradient of the straight line ( $(1 / 2)$ and the $y$-intercept (-) as the roots of the parabola. Her response is shown in figure 6 , where she (T24) writes that she has identified the values $\mathrm{x}_{1}=1 / 2$ and $x_{2}=\frac{7}{2}$.

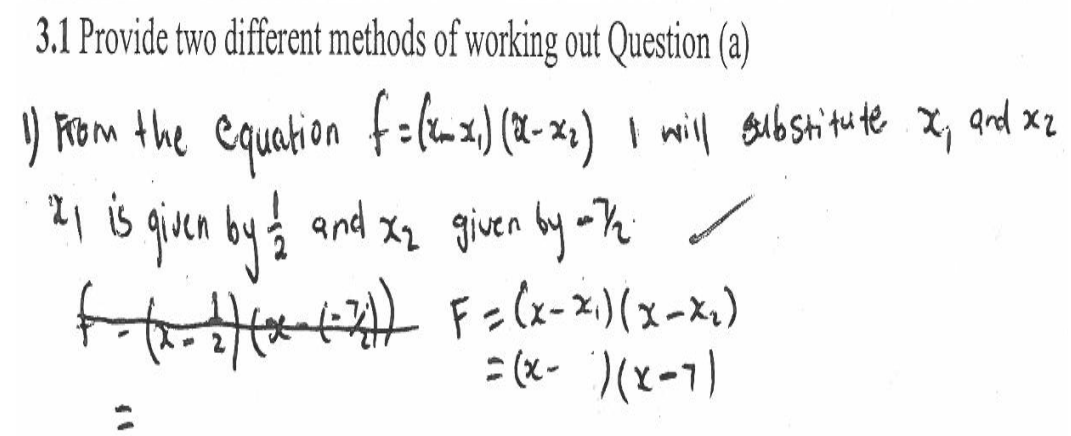

Figure 6. Written responses of participant T24.

In participant's T25 response in figure 7, an incorrect vertex form $\left[a(x-p)^{2}+q^{1 / 2}\right]$ was stated. An interesting revelation is found in her explanation of the process of finding the equation of the parabola using the incorrect vertex form, where she refers to the use of the equation of the line $[g(x)]$ as a method and then refers to the incorrect vertex form. 


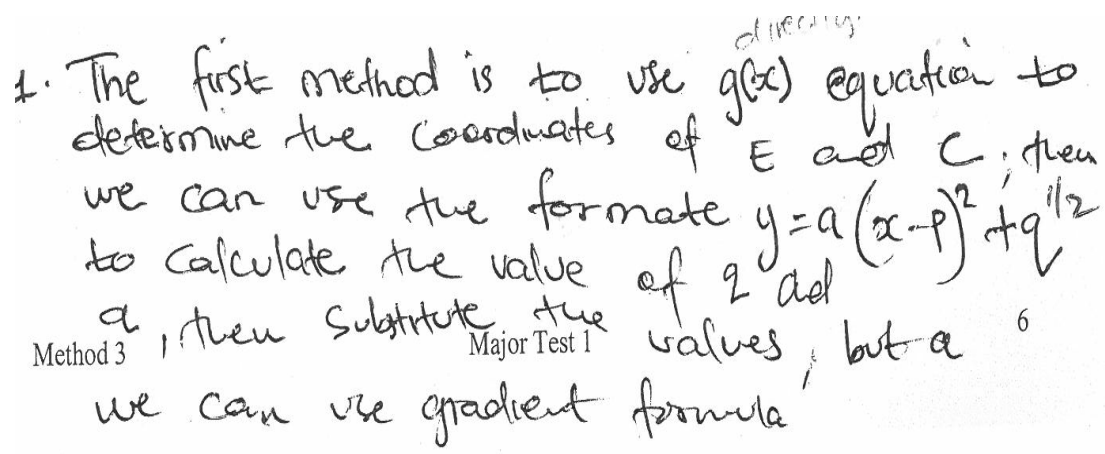

Figure 7. Written response using vertex method by participant T25.

In T25's response in figure 8 about her use of a second method to find the quadratic function, she presented the correct standard form of the equation. Again, an interesting explanation is given about the process of using the standard form to find the equation of the parabola.

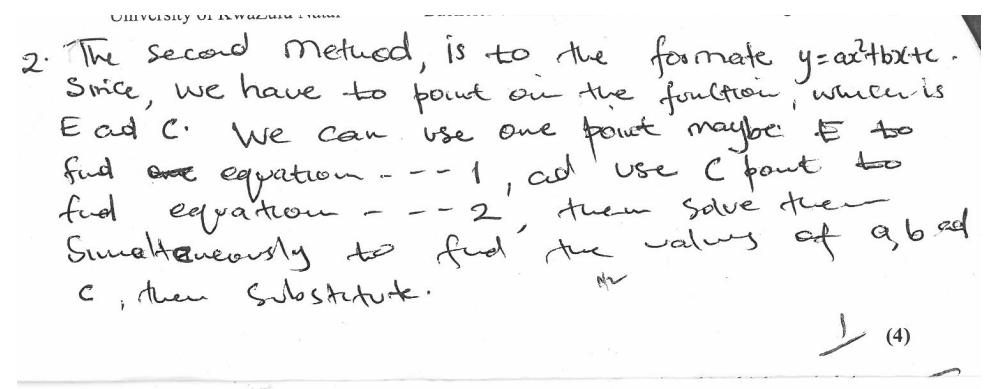

\section{Figure 8. Written response of participant T25.}

The participant was confused about many of the details stated. When asked during the interview, why she could not engage constructively on the question, T25 said she did not know such question will be asked and has forgotten the process of using the different methods to find the required equation of the parabola. It is hard to imagine how this concept will be taught in her classroom, if she does not receive any further instruction on the teaching of the concept. Although there were some differences that were observed between male and female participants, the issue of gender is beyond the scope of this research.

\section{Discussion}

The research showed that most common methods chosen by the participants, in trying to solve the problem on the quadratic function was the intercept method based on the equation $y=a\left(x-x_{1}\right)\left(x-x_{2}\right)$, where $x_{1}$ and $x_{2}$ are the $\mathrm{x}$-intercepts of the graph. The use of this method required them to identify the coordinates and then substitute into the intercept form of the equation, which may have been the least complicated option. This is similar to the findings of Ousby and Bowman (2008) who observed that the intercept form is the easiest way to find the equation of a parabola with two specific roots. However, it is a little different to the finding of Parent (2015) were participants preferred using the standard form to vertex and intercept methods. 
Ifunanya Julie Adaobi UBAH, Sarah BANSILAL. Pre-service mathematics teachers' knowledge of mathematics for teaching: Quadratic functions

PROBLEMS

OF EDUCATION

IN THE $21^{\text {st }}$ CENTURY Vol. 76, No. 6, 2018

860
The study by Bansilal et al., (2014) found that of the 253 practising teachers in their study, only $53 \%$ could present the equation of a quadratic function in vertex form. Similarly in this study, students also struggled with this form of the equation and only seven of the ten students who provided a correct form were able to complete the task correctly. Parent (2015) noted particular problems with the use of the vertex form. A common error made by the students in Parent's study was the confusion between the intercepts of graph and the coordinates of the turning point, which was also evident in the response by T5 in this study. Students had difficulties in identifying the various parameters associated with the different forms of quadratic functions. For instance, the written response of T24 in figure 7 shows that she associated $x_{1}=$ $1 / 2$ and $x_{2}=$ in the intercept method. Some participants displayed great difficulties in stating correctly the vertex and intercept forms of quadratic function, which indicates deep seated problems about the meaning of these parameters. Tall, Lima, \& Healy, (2014) observed that when learners have gaps in knowledge and skills that should have been developed earlier on, conceptual development of more complicated concepts is severely retarded.

In this study only $25(60 \%)$ were able to correctly work out the equation of a quadratic function. In terms of using two different methods, only 11(26\%) successfully applied two different methods to find the equation. This raises an important issue about the kind of knowledge that teachers need. Shulman seminal description of pedagogic content knowledge (PCK) described this phrase as: "subject matter knowledge for teaching...the ways of representing and formulating the subject that make it comprehensible to others... [It] includes an understanding of what makes the learning of specific topics easy or difficult; the conceptions or preconceptions that students of different ages bring with them to the learning of those most frequently taught topics and lessons." (Shulman, 1986, p. 9). Being able to produce the correct answers to questions based on school level content is just one small part of a mathematics teacher's task. Beyond that, a teacher should be able to decide upon a sequence of activities to introduce learners to new concepts; to link new content to big ideas in mathematics, to provide clear and unambiguous explanations; to design practice exercises and other consolidation activities as part of the teaching. Moreover, a teacher should be able to draw upon links between examples focusing on particular examples, counter examples, while also bringing in and making links across different representations so as to deepen their learners understanding of the concept. As research on teachers' pedagogic content knowledge indicates, there is much more than just knowing the common content knowledge (Shulman, 1986; Ball, Thames, \& Phelps, 2008). Teachers, who struggle to solve problems based on basic applications of well-known procedures, will be severely hampered in trying to teach their learners. They will not be able to recognise the demands of assessment items and will not be able to design well-structured assessments; neither will they be able to provide appropriate feedback to their learners, because PCK skills are constructed on the foundation of their content knowledge. Thus, the teachers' limited understanding is an impediment to the pedagogic content strategies that they will be able to draw upon in the class.

As research on teachers' pedagogic content knowledge indicates, there is much more than just knowing the common content knowledge (Shulman, 1986; Ball et al. 2008). This study showed that some pre-service teachers did not develop the insight that was necessary to make connections between the equations of the quadratic function and the graph of the corresponding parabola. The conditions under which the pre-service teachers learnt quadratic functions may be a factor that has made it difficult for them to acquire the necessary skills. Perhaps learning opportunities that are more conceptually grounded instead of the rule based method may be more successful and hence programs for pre-service teachers may need to offer such opportunities to students with poor mathematics backgrounds.

This research study has provided significant insights to the existing literature by identifying and analysing the pre-service teachers' knowledge of quadratic functions. The in-depth 
interviews provided evidence of how students struggled with making sense of the parameters used in the various forms that a quadratic function can be expressed. The results point to the need for pre-service teachers to be given challenging tasks which can help them interrogate their understanding of these fundamental concepts that they will be teaching in future. This is in line with Kilic's (2009) finding that suggested; teacher education programs need to offer courses that provide pre-service teachers with opportunities to review fundamental topics taught in secondary school mathematics.

\section{Conclusions}

This research focused on the written responses of 42 pre-service mathematics teachers to an item based on quadratic functions. The results showed that although 25 participants were able to determine the equation of a parabola using one method, most participants were unable to use two different methods to find the equation of the given parabola. The most common method chosen by students was the one based on the intercept form of the equation. Some students identified forms that the equation of a quadratic function could be expressed as but were unable to apply this to derive the equation. Many of the students were unable to even express the general equation in a form that correctly represented a quadratic function.

However, a large number of the pre-service teachers in this study struggled with finding the equation of a quadratic function using two methods. These results show that the pre-service teachers have not developed a robust understanding of this school level concept that they will be required to teach. This is an urgent problem that needs to be addressed especially because of the large numbers of under-prepared students who are training to become mathematics teachers even though they were not high achievers at school mathematics. It is clear that all stakeholders need to work together in devising interventions that can be used to offer greater support to those students and teachers who do not have a strong background in school mathematics.

As noted in the introductory remarks in this paper, that in some countries such as South Africa, students who do not have a sufficiently robust knowledge of basic mathematics are recruited into the teaching profession because of the large demand for qualified teachers. This raises a concern about whether it is possible for mathematics teacher education programmes to help pre-service teachers improve their understanding of the school level concepts they will need to teach. Most university programmes focus on developing knowledge of advanced mathematics because of the need for compliance with university accreditation structures. The assumption is that pre-service teachers have developed an understanding of the school mathematics content they need and hence this cannot form the focus of instruction at university. Based on this reality, it is important that pre-service teachers be given opportunities to improve on their knowledge of basic mathematics concepts in supportive of a well-structured intervention program. It is clear that newly qualified teachers still need sustained support and mentorship at their schools so that their mathematics knowledge for teaching can be improved.

\section{References}

Agyei, D. D., \& Voogt, J. (2012). Developing technological pedagogical content knowledge in preservice mathematics teachers through collaborative design. Australasian Journal of Educational Technology, 28 (4), 547-564.

Alex, J. K., \& Mammen, K. J. (2016). Geometrical sense making: Findings of analysis based on the characteristics of the van Hiele theory among a sample of South African Grade 10 learners. Eurasia Journal of Mathematics, Science and Technology Education, 12 (2), 173-188.

Alvanez, I., \& Gomez-Chacon, I. (2015). Understanding the algebraic variable: Comparative study of Mexican and Spanish students. Eurasia Journal of Mathematics, Science and Technology Education, 11 (6), 1507-1529. 
Ifunanya Julie Adaobi UBAH, Sarah BANSILAL. Pre-service mathematics teachers' knowledge of mathematics for teaching: Quadratic functions

\section{PROBLEMS \\ OF EDUCATION \\ IN THE $21^{\text {st }}$ CENTURY Vol. 76, No. 6, 2018 \\ 862}

Ball, D. L., Thames, M. H., \& Phelps, G. (2008). Content knowledge for teaching: What makes it special? Journal of Teacher Education, 59 (5), 389-407.

Bansilal S., Brijlall D., \& Mkhwanazi, T. (2014). An exploration of the common content knowledge of high school math teachers. Perspectives in Education, 32 (1), 34-50.

Benning, I., \& Agyei, D. D. (2016). Effect of using spread sheet in teaching quadratic functions on the performance of senior high school students. International Journal of Education, Learning and Development, 4 (1), 11-29.

Bloch, I. (2003). Teaching functions in graphic milieu: What forms of knowledge enable students to conjecture and prove? Educational Studies in Mathematics, 52, 3-28.

Bowie, L., \& Reed, Y. (2016). How much of what? An analysis of the espoused and enacted mathematics and English curricula for intermediate phase student teachers at five South African universities. Perspectives in Education, 34 (1), 102-119.

Celik, A. O., \& Guzel, E. B. (2017). Revealing Ozgur's thoughts of a quadratic function with a clinical interview: Concepts and their underlying reasons. International Journal of Research in Education and Science, 3 (1), 121-134.

Deacon, R. (2016). The initial teacher education project: Final report. Johannesburg: JET Education Services.

Dede, Y., \& Soybas, D. (2011). Pre-service mathematics teachers' experiences about function and equation concepts. EURASIA Journal of Mathematics, Science \& Technology Education, 7 (2), 89-102.

De Lima, R. N., \& Tall, D. (2008). Procedural embodiment and magic in linear equations. Educational Studies in Mathematics, 67, 3-18.

Department of Basic Education (2011). Curriculum and assessment policy statement grades 10-12: Mathematics. Pretoria: National Department of Education.

Didis, M., Bas, S., \& Erbas, A. (2011). Students' reasoning in quadratic equations with one unknown. Paper presented at: The 7th Congress of the European Society for Research in Mathematics Education; 2011 Feb 9-13; Rzeszów (Poland). Retrieved from: http://www.cerme7.univ. rzeszow.pl/WG/3/CERME7_WG3_Gozde.pdf

Iben, M. C. (2012). Ready to teach? Reflections on South African mathematics teacher education programme. Journal of Education, 56,163-195.

López, J., Robles, I., \& Martínez-Planell, R. (2016). Students' understanding of quadratic equations. International Journal of Mathematical Education in Science and Technology, 47 (4), 552-572.

Lowrie, T., \& Jorgensen, R. (2016). Pre-service teachers' mathematics content knowledge: Implications for how mathematics is taught in higher education. Teaching mathematics and its applications: An International Journal of IMA, 35 (4), 202-215.

Kilic, H. (2011). Preservice secondary mathematics teachers' knowledge of students. Turkish Online Journal of Qualitative Inquiry, 2, 17-35.

Kunene, H \& Bansilal, S. (2015) Grade 11 mathematics learners approaches to working with vertical and horizontal shifts of parabolas. In D. Huillet (Ed.), Proceedings of the 23rd Annual Meeting of the Southern African Association for Research in Mathematics, Science and Technology Education (SAARMSTE): Mathematics, Science and Technology Education for Empowerment and Equity (pp. 159-170). Maputo, Mozambique: SAARMSTE.

Leinhardt, G., Zaslavsky, O., \& Stein, M. K. (1990). Functions, graphs and graphing: Tasks, learning and teaching. Review of Educational Research, 60 (1), 1-64.

Mudaly, V., \& Rampersad, R. (2010). The role of visualisation in learners' conceptual understanding of graphical functional relationships. African Journal of Research in MST Education, 14 (1), 36 - 48.

Ma'rufi, (2016). Pedagogical Content Knowledge (PCK): Special knowledge type of teacher for effective learning (Case study of high school mathematics` teacher). International Journal of Library Science, 14 (2), 399-406.

NCTM, (2000). Principles and standards for school mathematics. Reston, VA: National Council of Teachers of Mathematics.

Ndlovu, Z., Amin, N., \& Samuel, M. A. (2017). Examining pre-service teachers' subject matter knowledge of school mathematics concepts. Journal of Education, (70), 46-72

Nielsen, L. E. J. (2015). Understanding quadratic functions and solving quadratic equations: An analysis of student thinking and reasoning. EURASIA Journal of Mathematics, Science and Technology Education, 3 (4), 351-361. 
Ifunanya Julie Adaobi UBAH, Sarah BANSILAL. Pre-service mathematics teachers' knowledge of mathematics for teaching: Quadratic functions

Ousby, J., Cross, R., \& Bowman, R. (2008). Cambridge Queensland Mathematics, B. Year 11. Australia: Cambridge University Press. Retrieved from: http://www.cambridge.edu.au.

Pender, W., Saddler, D., Shea, J., \& Ward, D. (2011). Cambridge 2 Unit mathematics year 11 enhanced version PDF textbook. Australia: Cambridge University Press. Available from: http://www. cambridge.org/

Parent, J. S. S. (2015). Students' understanding of quadratic functions: Learning from students' voices. A dissertation presented in partial fulfilment of the requirements for the degree of Doctor of Education, Vermont: University of Vermont.

Pournara, C., Hodgen, J., Adler, J., \& Pillay, V. (2015). Can improving teachers' knowledge of mathematics lead to gains in learners' attainment in mathematics? South African Journal of Education, 35 (3), $1-10$.

Prediger, S. (2010). How to develop mathematics for teaching and understanding: The case of meaning of the equal sign. Journal of Mathematics Teacher Education, 13 (1), 73-93.

Ratcliff, D. (2012). 15 methods of data analysis in qualitative research. Retrieved from https:// www.psychsoma.co.za/files/15methods.pdf

SAIRR (South African Institute of Race Relations) 2016. South Africa Survey. Johannesburg: SAIRR.

Sauro, J. (2015). Five types of qualitative methods. Denver, Colorado. Available from: https:// measuring.com/quali-methods/.

Shulman, L. (1986). Those who understand knowledge growth in teaching. Educational Researcher, 15 (2), 4-14.

Sibuyi, C. D. (2012). Effective teachers' pedagogical content knowledge in teaching quadratic functions in mathematics. A dissertation submitted in partial fulfilment of the requirement for the degree M.Ed Assessment and Quality Assurance, Pretoria: University of Pretoria.

Siyepu, S. W. (2013). An exploration of students' errors in derivatives in a university of technology. The Journal of Mathematical Behaviour, 32 (3), 577-592.

Tall, D. (2013). How humans learn to think mathematically: Exploring the three worlds of Mathematics. Cambridge: Cambridge University Press.

Tall, D., de Lima, R. N., \& Healy, L. (2014). Evolving a three-world framework for solving algebraic equations in the light of what a student has met before. The Journal of Mathematical Behavior, $34,1-13$.

Taylor, N., \& Taylor, S. (2015). Teacher knowledge and professional habits. In N Taylor, S. Van de Berg \& T. Mabogoane (Eds). What makes schools effective? Report of South Africa's national school effectiveness study. Cape Town: Pearson.

Yeo, J., Seng, T. K., Ye, L. C., \& Chew, I. (2013). New syllabus additional mathematics Textbook (Eds). Singapore: Shinglee Publishers Pte Ltd.

Yuksel, D., \& Danyal, S. (2011). Pre-service mathematics teachers' experiences about function and equation concepts. Eurasia Journal of Mathematics, Science and Technology, 7 (2), 89-102.

Zaslavsky, O. (1997). Conceptual obstacles in the learning of quadratic functions. Focus on Learning Problems in Mathematics, 19 (1), 20-44.

Vandebrouck, F. (2018). Activity theory in French didactic research. Invited lectures from the $13^{\text {th }}$ International Congress on Mathematical Education. Retrieved from: https://hal.archivesouvertes.fr/hal-01766869.

Received: July 01, 2018

Accepted: October 09, 2018

Ifunanya Julie Adaobi Ubah

Sarah Bansilal
PhD, Post Doctoral scholar, University of Kwazulu-Natal, Private Bag X54001, Durban, KwaZulu-Natal Province, South Africa. E-mail: adaichieify2000@gmail.com

PhD, Professor, Head of Department of Mathematics Education, School of Education, University of KwaZulu-Natal, Durban, KwaZulu-Natal, South Africa.

E-mail: BansilalS@ukzn.ac.za
PROBLEMS
OF EDUCATION
IN THE 21 $1^{\text {st }}$ CENTURY
Vol. 76, No. 6, 2018

863 